\title{
Prevalence and Associated Factors of Dental Trauma in Six- Year-Old School-Children
}

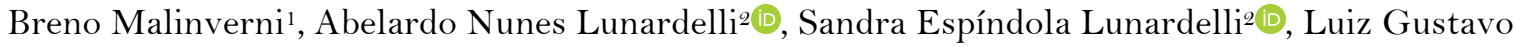

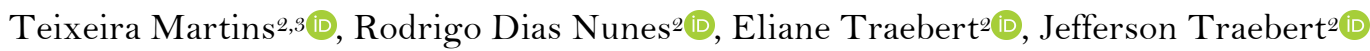

\begin{abstract}
${ }^{1}$ School of Dentistry, University of Southern Santa Catarina, Palhoça, SC, Brazil.
${ }^{2}$ Post-Graduate Program in Health Sciences, University of Southern Santa Catarina, Palhoça, SC, Brazil.

${ }^{3}$ School of Dentistry, University of the Extreme South of Santa Catarina, Criciúma, SC, Brazil.
\end{abstract}

Correspondence: Jefferson Traebert, Avenida Pedra Branca, 25, Cidade Universitária, Pedra Branca, Palhoça, SC, Brazil. 88132-270. E-mail: jefferson.traebert@gmail.com

Academic Editor: Alessandro Leite Cavalcanti

Received: 21 July 2020 / Review: 31 August 2020 / Accepted: 27 September 2020

How to cite: Malinverni B, Lunardelli AN, Lunardelli SE, Martins LGT, Nunes RD, Traebert E, et al. Prevalence and associated factors of dental trauma in six-year-old school-children. Pesqui Bras Odontopediatria Clín Integr. 2021; 21:e0171. https://doi.org/10.1590/pboci.2021.033

\begin{abstract}
Objective: To estimate the prevalence and associated factors of dental trauma in 6-year-old school children in the city of Palhoça, Brazil. Material and Methods: Cross-sectional study nested in a cohort study. It involved a representative sample of school children born in 2009, residing in the municipality and regularly enrolled in public and private schools $(n=1,102)$. Clinical data were obtained through oral exams. To evaluate the incisal overjet, the distance in millimeters was measured horizontally from the labial surface of the lower central incisor to the labial surface of the upper incisor. Bivariate analyses were performed using the Chi-square test, with a p-value $<0.05$ considered statistically significant. Multivariate analyses using Poisson Regression were performed to identify independent associations between the prevalence and the independent variables studied. Results: Prevalence of dental trauma was 4.2\% (95\% CI 3.0-5.4). Dental trauma was statistically associated with studying in a private school $(\mathrm{PR}=1.03 ; 95 \% \mathrm{CI} 1.01-1.06)$ $(p=0.016)$ and with inadequate lip coverage $(P R=1.08 ; 95 \%$ CI 1.01-1.14) $(p=0.016)$. Conclusion: The prevalence of $4.2 \%$ of dental trauma in six-year-old children, associated with inadequate and greater lip coverage in children from private schools should be taken into account, since most teeth at this stage are newly erupted.
\end{abstract}

Keywords: Epidemiology; Tooth Injuries; Tooth Fractures; Dentition, Mixed. 


\section{Introduction}

Dental trauma (DT) is considered by the World Health Organization (WHO) to be a worldwide public health issue [1]. Epidemiological studies show a drop in the prevalence of dental caries in children which rates are not as high as they have been for several decades [2-4]. On the other hand, there is a considerable prevalence of DT among Brazilian preschool children [5-7]. A study reported in the international literature, aiming at identifying DT epidemiology in both primary and permanent dentition, found that $25 \%$ of all school-age children had already suffered some type of DT, and that practically $33 \%$ of adults had also experienced DT before they were 19 years old [8]. This prevalence reveals the need to investigate DT causes and associated factors, and consequently optimize prevention of their occurrence [9].

The high rates of violence, traffic accidents and sports activities are cited as important factors for DT, as they have contributed to the increase in their occurrence [10]. When we review the location of the occurrences we find that the traumatic experience usually occurs at home, on the street, school, parks or squares [11]. Regarding etiology, falls, traffic accidents, contact sports and violence are the mostly reported factors. However, there are also less common types of causes, such as iatrogenesis of hospital procedures, physical abuse in childhood, unspecific shocks, dizziness, psychic changes and epilepsy [11].

It is important that appropriate measures be taken promptly after the occurrence of DT, aiming at a good prognosis in relation to the affected tissues. Problems during the rescue, depending on the type and intensity degree of the impact can lead to the loss of the dental element. It is, therefore, necessary to offer guidelines and prepare the population on the necessary care at the time of the accident [10].

Predisposing factors contribute to increased susceptibility to DT, such as marked incisal overjet and inadequate lip coverage. In addition, the risk increases in males [5,7,12].

It is important to highlight that DT not only affects the physical part with injury to the face and teeth, but also, psychologically causing anxiety and distress not only for the child, but also for the parents [6]. In relation to the physical-functional aspect, a lesion located in the anterior region of the oral cavity can lead to physical disability, such as difficulty in chewing, phonation or both. In the psychosocial aspect, it can provide social and psychological embarrassment, such as smiling avoidance, affecting social relationships. In addition, the high prevalence of DT has been responsible for a high demand for emergency dental services, generating high public costs [6].

The objective of this study was to estimate the prevalence and factors associated with DT in six-yearold school children in the city of Palhoça, Brazil. This age was chosen to enable the analysis of DT at the beginning of mixed dentition, an age that has been little studied and with little data available in the scientific literature.

\section{Material and Methods}

Study Design

The study population consisted of six-year-old children regularly enrolled in schools and residing in the municipality of Palhoça, SC, Brazil in 2015. The municipality is located $14 \mathrm{~km}$ from Florianópolis, the capital of the Santa Catarina State. The resident population of Palhoça in 2015 was estimated at 157,833 inhabitants [13].

A cross-sectional study was carried out nested in the study named Coorte Brasil Sul [14], conducted by the Post-Graduate Program in Health Sciences at the Universidade do Sul de Santa Catarina. A total of 
1,102 children who had oral health data composed the sample, out of a total of 1,270 students being followed up $[14]$.

\section{Data Collection}

Clinical data were obtained through oral exams using the O'Brien criteria [15]. To evaluate the incisal overjet, the distance in millimeters was measured horizontally from the labial surface of the lower central incisor to the labial surface of the upper incisor. WHO-type periodontal probes were used to verify the measurements. Regarding lip coverage, with the student mentally reading a document, without knowing that he was being observed, adequate lip coverage was considered when the lips touched each other, completely covering the anterior teeth. No lip coverage was considered when the examiner was able to observe the teeth through the lips at rest.

The examinations were carried out in a school environment, with natural light, observing all the biosafety criteria [16]. The data collection team was composed of nine Dental Surgeons (DS) and nine Oral Health Assistants (OHA), all of whom work for the Municipality of Palhoça, SC. The team was properly trained and calibrated in order to obtain uniformity and diagnostic reproducibility. Four hours training and calibration sessions were conducted and a closing meeting was held to present the results. The calibration process was carried out using the "in lux" methodology [17,18] and the Kappa index was used to measure intra- and inter-examiner diagnostic reproducibility. The team was considered calibrated when the Kappa values were greater than 0.7 for all tests. A total of $5 \%$ of the sample was examined in duplicate with the purpose of diagnostic monitoring during collection. Other information collected was gender and the type of school in which the student was enrolled (public or private).

\section{Data Analysis}

The data were inserted into Excel spreadsheets and after correcting the inconsistencies, they were exported to the IBM SPSS ${ }^{\circledR} 18.0$ program where they were analyzed. A descriptive analysis of the studied variables was carried out. Bivariate analyses were performed using the Chi-square test, with a p-value $<0.05$ considered statistically significant. Multivariate analyses using Poisson Regression with robust estimators were performed to identify independent associations between the prevalence of DT and the independent variables (gender, type of school, incisal overjet and lip coverage). Prevalence ratios (PR) and their relevant confidence intervals $(95 \%)$ were estimated.

\section{Ethical Clearance}

A free and informed consent form describing the investigation objectives, data confidentiality and voluntary participation was forwarded to the participants' parents. The results of clinical examinations were made readily available to all participants. Reports signed by the research team were delivered to parents and they reported any identified health problems. The investigation project was submitted to and approved by the Research Ethics Committee with Human Beings of the Universidade do Sul de Santa Catarina under opinion number 38240114.0 .0000 .5369 .

\section{Results}

The total number of children examined was 1,102 , yielding a response rate of $86.7 \%$ compared to the total number of children being followed up. The main reasons for losses were the parents' non-permission and 
the child's absence from school on the exam days. The degree of diagnostic reproducibility showed Kappa values greater than 0.70 , calculated from tooth to tooth, both intra and inter-examiner.

Of the total participants, $50.2 \%$ were male and $83.6 \%$ studied in public schools. These and other proportions related to clinical issues such as incisal overjet and lip coverage are shown in Table 1. The prevalence of DT found was 4.2\% (95\% CI 3.0; 5.4). Out of the total of 55 teeth that presented DT, 32 (60.4\%) presented fracture only in the enamel and 13 (18.9\%) enamel-dentin fracture (Table 2$)$.

Table 1. Sample distribution according to socio-demographic and clinical variables.

\begin{tabular}{lcc}
\multicolumn{1}{c}{ Variables } & $\mathbf{N}$ & $\mathbf{\%}$ \\
\hline $\begin{array}{l}\text { Gender }[\mathrm{n}=1,102] \\
\quad \text { Male }\end{array}$ & 553 & 50.2 \\
$\quad$ Female & 549 & 49.8 \\
Type of School $[\mathrm{n}=1,102]$ & & \\
$\quad$ Public & 921 & 83.6 \\
$\quad$ Private & 181 & 16.4 \\
Incisal Overjet $[\mathrm{n}=1,099]$ & & \\
$\quad \leq 3 \mathrm{~mm}$ & 660 & 60.1 \\
$\quad$ >3mm & 439 & 39.9 \\
Lip Coverage $[\mathrm{n}=1,081]$ & & \\
$\quad$ Adequate & 918 & 84.9 \\
$\quad$ Inadequate & 163 & 15.1 \\
\hline
\end{tabular}

Table 2. Absolute and relative distribution of types of dental trauma.

\begin{tabular}{lcccc}
\multicolumn{1}{c}{ Variables } & School Children & \multicolumn{2}{c}{ Teeth } \\
& N & $\%$ & N & $\%$ \\
\hline Enamel Fracture & 29 & 63.0 & 32 & 60.3 \\
Enamel and Dentin Fracture & 10 & 21.8 & 13 & 24.5 \\
Fracture with Pulp Involvement & 5 & 10.8 & 6 & 11.4 \\
Tooth Absence due to Trauma & 2 & 4.4 & 2 & 3.8 \\
\multicolumn{1}{c}{ Total } & 46 & 100.0 & 53 & 100.0 \\
\hline
\end{tabular}

The groups of teeth most affected were the upper central incisors (70.9\%), followed by the upper lateral incisors $(21.9 \%)$ in both the primary and permanent dentition. The values for the other teeth are shown in Table 3.

Table 3. Prevalence of dental trauma according to tooth and dentition.

\begin{tabular}{ccc}
\hline Variables & N & \% \\
\hline Primary Dentition & 5 & 9.1 \\
52 & 8 & 14.5 \\
51 & 5 & 9.1 \\
61 & 3 & 5.5 \\
62 & - & - \\
72 & 1 & 1.8 \\
71 & - & - \\
81 & - & - \\
82 & & 5.5 \\
Permanent Dentition & 3 & 21.8 \\
12 & 12 & 25.5 \\
21 & 14 & 1.8
\end{tabular}




\begin{tabular}{cccc}
32 & - & - \\
31 & 1 & 3.8 \\
41 & 2 & - \\
42 & - & 100.0 \\
\hline
\end{tabular}

The results of the association studies showed that the gender variable was not statistically associated $(\mathrm{p}=0.238)$. With regard to the type of school, which is a proxy for socioeconomic conditions, children who studied in private schools had a statistically higher prevalence when compared to those in public schools $(p=0.001)$. The incisal overjet measurement greater than $3 \mathrm{~mm}(\mathrm{p}=0.042)$ and inadequate lip coverage $(\mathrm{p}=0.001)$ were also associated with dental trauma (Table 4$)$.

Table 4. Result of bivariate analysis.

\begin{tabular}{|c|c|c|c|c|c|c|}
\hline \multirow{3}{*}{ Variables } & \multicolumn{4}{|c|}{ Dental Trauma } & \multirow{3}{*}{$\begin{array}{l}\text { Total } \\
\text { N (\%) }\end{array}$} & \multirow{3}{*}{ p-value } \\
\hline & \multicolumn{2}{|c|}{ Yes } & \multicolumn{2}{|c|}{ No } & & \\
\hline & $\mathrm{N}$ & $\%$ & $\mathrm{~N}$ & $\%$ & & \\
\hline Gender & & & & & & 0.238 \\
\hline Male & 27 & 4.9 & 526 & 95.1 & $553(50.2)$ & \\
\hline Female & 19 & 3.5 & 530 & 96.5 & $549(49.8)$ & \\
\hline Type of School & & & & & & 0.001 \\
\hline Public & 29 & 3.1 & 892 & 16.9 & $921(83.6)$ & \\
\hline Private & 17 & 9.4 & 164 & 90.6 & $181(16.4)$ & \\
\hline Incisal Overjet & & & & & & 0.042 \\
\hline$\leq 3 \mathrm{~mm}$ & 21 & 3.2 & 639 & 96.8 & $660(60.1)$ & \\
\hline$>3 \mathrm{~mm}$ & 25 & 5.8 & 414 & 94.3 & 439 (39.9) & \\
\hline Lip Coverage & & & & & & 0.001 \\
\hline Adequate & 38 & 3.6 & 1.014 & 16.4 & $918(84.9)$ & \\
\hline Inadequate & 8 & 17.4 & 38 & 82.6 & $163(15.1)$ & \\
\hline
\end{tabular}

The results of the multivariate analysis showed that children from private schools had a statistically higher and independent prevalence of DT compared to children from public schools (PRa $=1.03$; 95\% CI 1.011.06) ( $\mathrm{p}=0.016)$. The same happened with those children with inadequate lip coverage $(\mathrm{PRa}=1.08 ; 95 \% \mathrm{CI}$ 1.01-1.14) regardless of the other variables studied. The variables incisal overjet and lip coverage were shown to be collinear $(\mathrm{p}<0.001)$, thus opting to maintain lip coverage in the adjusted model (Table 5).

Table 5. Results of the crude and adjusted analysis for the prevalence of dental trauma in 6 year-olds.

\begin{tabular}{|c|c|c|c|c|}
\hline Variables & PR. (CI 95\%) & p-value & PR $($ CI 95\%) & p-value \\
\hline Gender & & 0.238 & & 0.207 \\
\hline Male & 1.00 & & 1.00 & \\
\hline Female & $0.99(0.98-1.01)$ & & $0.99(0.98-1.01)$ & \\
\hline Type of School & & $<0.001$ & & 0.016 \\
\hline Public & 1.00 & & 1.00 & \\
\hline Private & $1.04(1.01-1.00)$ & & $1.03(1.01-1.06)$ & \\
\hline Incisal Overjet & & 0.042 & \# & \\
\hline$\leq 3 \mathrm{~mm}$ & 1.00 & & & \\
\hline$>3 \mathrm{~mm}$ & $1.02(1.01-1.03)$ & & & \\
\hline Lip Coverage & & $<0.001$ & & 0.016 \\
\hline Adequate & 1.00 & & 1.00 & \\
\hline Inadequate & $1.07(1.01-1.14)$ & & $1.08(1.01-1.14)$ & \\
\hline
\end{tabular}

$\mathrm{PR}_{\mathrm{c}}=$ Crude Prevalence Ratio; $\mathrm{PR}_{\mathrm{a}}=$ Adjusted Prevalence Ratio; CI 95\% = 95\% Confidence Interval; \#The variables incisal overjet and lip coverage were shown to be collinear $(\mathrm{p}<0.001)$. We opted to maintain lip coverage in the adjusted model. 


\section{Discussion}

The good response rate, the calibration process and the intra and inter-examiner reproducibility data ensure good internal data validity. There are few epidemiological studies of DT focused on mixed dentition. A study carried out with school children aged 5 and 6 years $(n=684)$ in the city of Barueri, Brazil $[5]$, showed a $52.3 \%$ DT prevalence, which indicates a significant difference in the prevalence found in this study (4.2\%). However, another study conducted in the municipality of Tubarão, Brazil, with 7 and 8-year-old students $(\mathrm{n}=$ 1,435) [19] who were in the initial eruption period of the permanent incisors, showed a prevalence of $9.6 \%$, close to that of the present study.

In this phase, certain factors can be brought into the picture to explain the different prevalences found in the literature. Exfoliation of primary teeth that suffered trauma prior to the data collection and the eruption period of the permanent anterior teeth are factors that may explain the difference in the prevalences reviewed [19]. In addition, the diversity of classifications used in the studies makes it difficult to compare the results, so that the development of standard protocols would allow a better data comparison [6].

It is important to note that children with a history of DT have a higher chance of new episodes. Adolescents with a history of DT were almost five times more likely to experience new occurrences compared to adolescents who never suffered DT [20]. A recent meta-analysis indicated that the risk of a new DT occurrence in individuals who had already suffered DT in the past was twice as high [21]. It is important to identify DT early, from the beginning of permanent dentition, as proposed in this work. Early identification of children with DT enables the consequent intervention with preventive measures against new episodes of DT. In addition, DT diagnosis in primary teeth is of fundamental importance as a risk indicator for DT in future permanent teeth [22].

Although most studies indicate a greater association of the prevalence of DT and the male gender, both in permanent and primary dentition [5,7], in this study no statistically significant association was observed. This could, hypothetically, be explained by the fact that currently contact sports and other behaviors previously typically restricted to boys are also being practiced by girls. Thus, the risk of gender-related DT would be equalized [20,23-26].

The identification of a statistically significant association between the prevalence of DT and the private school may be ascribed to socioeconomic conditions. The type of school attended by the child may reflect different family economic conditions [27]. This finding may be related to a greater facility of children with better socioeconomic conditions having greater access to equipment such as bicycles, skateboards, skates, scooters, when compared to those of families with lower socioeconomic conditions [26,28]. However, it is difficult to see the use of protective and safety equipment such as helmets and mouth guards in contact sports or risky games, which could prevent traumatic episodes [6,17,29].

Among the most studied clinical factors, variables related to occlusal conditions, such as the incisal overjet and the adequacy of lip coverage are the most prominent [30-33]. In this study, these variables were shown to be statistically associated. The findings about overjet and inadequate lip coverage corroborates with other studies [10,30,34,35]. A meta-analysis focused on observational studies has shown that marked overjet can double or even triple the risk of trauma to the anterior teeth. Measures can be taken to minimize the risk of DT, ranging from orthodontic treatment to protection through mouth guards, in addition to tutors and parents' guidance [36].

Among the limitations of this study, we can mention the large number of examiners used, which could generate a measurement bias. However, precautions were taken, such as examiners' training and calibration exercises, in addition to monitoring the diagnostic variability in the data collection process. 
Even so, the prevalence results should be observed with caution, since the low DT rate may be a possible reflection of the under-studied age group. Therefore, further studies in the same age group are necessary in order to compare the prevalence of the occurrence of DT in the six-year-old population.

\section{Conclusion}

The prevalence of $4.2 \%$ of DT in six-year-old children, associated with increased incisal overjet or inadequate and large lip coverage deficiency in children from private schools should be taken into account, since most teeth at this age are newly erupted.

\section{Authors' Contributions}

\begin{tabular}{|c|c|c|}
\hline BM & (1) & $\begin{array}{l}\text { Conceptualization, Methodology, Formal Analysis, Writing - Original Draft and Writing - } \\
\text { Review and Editing. }\end{array}$ \\
\hline ANL & https://orcid.org/0000-0002-3052-8020 & Writing - Original Draft and Writing - Review and Editing. \\
\hline SEL & https://orcid.org/0000-0002-7836-6083 & Formal Analysis, Writing - Original Draft and Writing - Review and Editing. \\
\hline LGTM & https://orcid.org/0000-0003-0898-1440 & Writing - Original Draft and Writing - Review and Editing. \\
\hline RDN & https://orcid.org/0000-0002-2261-8253 & Formal Analysis, Writing - Original Draft and Writing - Review and Editing. \\
\hline ET & https://orcid.org/0000-0001-9667-7216 & $\begin{array}{l}\text { Conceptualization, Methodology, Investigation, Writing - Original Draft and Writing - Review } \\
\text { and Editing. }\end{array}$ \\
\hline JT & https://orcid.org/o000-0002-7389-985X & $\begin{array}{l}\text { Conceptualization, Methodology, Formal Analysis, Writing - Original Draft and Writing - } \\
\text { Review and Editing. }\end{array}$ \\
\hline
\end{tabular}

\section{Financial Support}

FAPESC - Grant Number 2016 TR22 and PROSUC/CAPES - Financing Code 001.

\section{Conflict of Interest}

The authors declare no conflicts of interest.

\section{Data Availability}

The data used to support the findings of this study can be made available upon request to the corresponding author.

\section{References}

[1] World Health Organization. The World Oral Health Report 2003 WHO Global Oral Health Programme. Available from: https://www.who.int/oral_health/media/en/orh_reporto3_en.pdf. [Accessed on March 20, 2019].

[2] Brasil. Ministério da Saúde. SB Brasil 2010: Pesquisa Nacional de Saúde Bucal. Brasília: Ministério da Saúde, 2012. [In Portuguese]

[3] Narvai PC, Frazão P, Roncalli AG, Antunes LF. Dental caries in Brazil: decline, polarization, inequality and social exclusion. Rev Panam Salud Publica 2006; 19(6):385-93.

[4] Agnelli PB. Variation of brazilian CPOD index during the 1980 to 2010 period. Rev Bras Odontol 2015; 72(1/2):10-5.

[5] Berti GO, Hesse D, Bonifácio CC, Raggio DP, Bonecker MJS. Epidemiological study of traumatic dental injuries in 5to 6-year-old Brazilian children. Braz Oral Res 2015; 29(1):1-6. https://doi.org/10.1590/1807-3107BOR-2015.vol29.0103

[6] Traebert J, Claudino D. Epidemiology of traumatic dental injuries in children: the brazilian scientific production. Pesqui Bras Odontopediatria Clin Integr 2012; 12(2):263-72. https://doi.org/10.4034/PBOCI.2012.122.17

[7] Rodrigues AS, Castilho T, Azeredo LAA, Antunes LS. Epidemiological Profile of Dental Trauma in Children and Adolescents in Brazil. UNOPAR Cient Ciênc Biol Saúde 2015; 17 (4):267-78.

[8] Glendor U. Epidemiology of traumatic dental injuries - a 12 year review of the literature. Dent Traumatol 2008; 24(6):603-11. https://doi.org/10.1111/j.1600-9657.2008.00696.x

[9] Diangelis AJ, Andreasen JO, Ebeleseder KA, Kenny DJ, Trope M, Sigurdsson A, et al. Guidelines for the management of traumatic dental injuries: 1. Fractures and luxations of permanent teeth. Pediatr Dent 2016; 38(6):358-68.

[10] Mota LQ, Targino AGR, Lima MGGC, Farias JFG, Silva ALA, Farias FFG. Evaluation of dental trauma in schoolchildren of the city of João Pessoa, PB, Brazil. Pesqui Bras Odontopediatria Clin Integr 2011; 11(2):217-22. https://doi.org/10.4034/PBOCI.2011.112.11

[11] Levin L, Zadik Y. Education on and prevention of dental trauma: It's time to act! Dent Traumatol 2012; 28(1):49-54. https://doi.org/10.1111/j.1600-9657.2011.01060.x 
[12] Corrêa-Faria P, Martins CC, Bönecker M, Paiva SM, Ramos-Jorge ML, Pordeus IA. Clinical factors and sociodemographic characteristics associated with dental trauma in children: a systematic review and meta-analysis. Dent Traumatol 2016; 32(5):367-78. https://doi.org/10.1111/edt.12268

[13] Instituto Brasileiro de Geografia e Estatística. Santa Catarina. Palhoça. Estimativa da população. 2015. Available from: www.cidades.ibge.gov.br. [Accessed on September 20, 2015]. [In Portuguese]

[14] Traebert J, Lunardelli SE, Martins LGT, Santos K, Nunes RD, Lunardelli AN, et al. Methodological description and preliminary results of a cohort study on the influence of the first 1000 days of life on the children 's future health. Ann Brazilian Acad Sci 2018; 90(3):3105-14. https://doi.org/10.1590/0001-3765201820170937

[15] O'Brien M. Children's dental health in United Kingdon 1993. Office of population censuses and surveys. London: Her Majesty's Stationery Office, 1994.

[16] Brasil. Ministério da Saúde. Controle de Infecções e a Prática Odontológica em Tempos de AIDS. Brasília: Ministério da Saúde, 2000. [In Portuguese]

[17] World Health Organization. The Oral Health Report. Geneva: WHO, 1997.

[18] Chen Y, Lee W, Ferretti GA, Slayton RL, Nelson S. Agreement between photographic and clinical examinations in detecting developmental defects of enamel in infants. Am Assoc Public Heal Dent 2013; 73(3):204-9. https://doi.org/10.1111/jphd.12014

[19] Traebert J, Hemkemeier I, Lacerda JT. Traumatic injuries in permanent newly erupted teeth: prevalence and associated factors in schoolchildren of Tubarão, Brazil. Rev Odontol UNESP 2008; 37(4):363-9.

[20] Ramos-Jorge ML, Peres MA, Traebert J, Ghisi CZ, de Paiva SM, Pordeus IA, et al. Incidence of dental trauma among adolescents: a prospective cohort study. Dent Traumatol 2008; 24(2):159-63. https://doi.org/10.1111/j.16009657.2007.00533.x

[21] Magno MB, Neves AB, Ferreira DM, Pithon MM, Maia LC. The relationship of previous dental trauma with new cases of dental trauma. A systematic review and meta-analysis. Dent Traumatol 2019; 35(1):3-14. https://doi.org/10.1111/edt.12449

[22] Goettems ML, Brancher LC, Costa CT, Bonow MLM, Romano AR. Does dental trauma in the primary dentition increases the likelihood of trauma in the permanent dentition? a longitudinal study. Clin Oral Investig 2017; 21(8):2415-20. https://doi.org/10.1007/s00784-016-2037-3

[23] Traebert J, Peres MA, Blank V, Boell RS, Pietruza JA. Prevalence of traumatic dental injury and associated factors among 12-year-old school children in Florianopolis, Brazil. Dent Traumatol 2003; 19(1):15-8. https://doi.org/10.1034/j.1600-9657.2003.00138.x

[24] Paiva PCP, Paiva HN, Jorge KO, de Oliveira Filho PM. Cross-sectional study on treatment needs, etiology and occurrence of traumatic dental injuries among 12-yearold schoolchildren in Montes Claros, Brazil. Arq Odontol 2013; 49(1):19-25. https://doi.org/10.7308/aodontol/2013.49.1.03

[25] Traebert J, Facenda F, de Lacerda JT. Prevalence and treatment needs due to traumatic dental injuries in schoolchildren of Joaçaba, SC. Rev Fac Odontol Porto Alegre 2008; 12(3):10-2. https://doi.org/10.22456/21770018.3261

[26] Alves MTG, Soares JF. School effectiveness research: methodological contributions to the Sociology of Education. Soc Estado 2007; 22(2):435-73. https://doi.org/10.1590/S0102-69922007000200008

[27] Marcenes W, Zabot NE, Traebert J. Socio-economic correlates of traumatic injuries to the permanent incisors in schoolchildren aged 12 years in Blumenau, Brazil. Dent Traumatol 2001; 17(5):222-6. https://doi.org/10.1034/j.1600-9657.2001.170507.x

[28] Cortes MI, Marcenes W, Sheiham A. Prevalence and correlates of traumatic injuries to the permanent teeth of school-children aged 9-14 years in Belo Horizonte, Brazil. Dent Traumatol 2001; 17(1):22-6. https://doi.org/10.1034/j.1600-9657.2001.170105.x

[29] Grimm S, Frazão P, Antunes JL, Castellanos RA, Narvei PC. Dental injury among Brazilian schoolchildren in the state of São Paulo. Dent Traumatol 2004; 2O(3):134-8. https://doi.org/10.1111/j.1600-4469.2004.00238.x

[30] Frujeri ML, Frujeri JA, Bezerra AC, Cortes MI, Costa Jr ED. Socio-economic indicators and predisposing factors associated with traumatic dental injuries in schoolchildren at Brasília, Brazil: a cross-sectional, population-based study. BMC Oral Health 2014; 14:91. https://doi.org/10.1186/1472-6831-14-91

[31] Zaleckiene V, Peciuliene V, Brukiene V, Drukteinis S. Traumatic dental injuries: etiology, prevalence and possible outcomes. Stomatologija 2014; 16(1):7-14.

[32] Viegas CM, Paiva SM, Carvalho AC, Scarpelli AC, Ferreira FM, Pordeus IA. Influence of traumatic dental injury on quality of life of Brazilian preschool children and their families. Dent Traumatol 2014; 30(5):338-47. https://doi.org/10.1111/edt.12091

[33] Bastone EB, Freer TJ, McNamara JR. Epidemiology of dental trauma: a review of the literature. Aust Dent J 2000; 45(1):2-9. https://doi.org/10.1111/j.1834-7819.2000.tb00234.x

[34] Traebert J, Almeida ICS, Garghetti C, Marcenes W. Prevalence, treatment needs, and predisposing factors for traumatic injuries to permanent dentition in 11-13-year-old schoolchildren. Cad Saúde Pública 2004; 20(2):403-10. https://doi.org/10.1590/S0102-311X2004000200007 
[35] Traebert J, Bittencourt DD, Peres KG, Peres MA, De Lacerda JT, Marcenes W. Aetiology and rates of treatment of traumatic dental injuries among 12-year-old school children in a town in southern Brazil. Dent Traumatol 2006; 22(4):173-8. https://doi.org/10.1111/j.1600-9657.2006.00359.x

[36] Petti S. Over two hundred million injuries to anterior teeth attributable to large overjet: a meta-analysis. Dent Traumatol 2015; 31(1):1-8. https://doi.org/10.1111/edt.12126 